\title{
Erratum to: Association of glucose metabolism with diastolic function along the diabetic continuum
}

\author{
R. Stahrenberg • F. Edelmann • M. Mende • A. Kockskämper • H. D. Düngen • \\ M. Scherer • M. M. Kochen • L. Binder • C. Herrmann-Lingen • L. Schönbrunn • \\ G. Gelbrich • G. Hasenfuß • B. Pieske • R. Wachter
}

Published online: 28 January 2011

(C) Springer-Verlag 2011

\section{Erratum to: Diabetologia}

DOI 10.1007/s00125-010-1718-8

Unfortunately L. Schönbrunn was inadvertently omitted from the author list of the original version of this paper. The correct author list is shown above.

The online version of the original article can be found at http://dx.doi. org/10.1007/s00125-010-1718-8.

R. Stahrenberg $\cdot$ F. Edelmann $\cdot$ L. Schönbrunn $\cdot$ G. Hasenfuß $•$

M. Scherer $\cdot$ M. M. Kochen

R. Wachter $(\bowtie)$

Department of Cardiology and Pneumology,

University of Goettingen,

37075 Goettingen, Germany

e-mail: wachter@med.uni-goettingen.de

Department of General Practice, University of Goettingen,

Goettingen, Germany

M. Mende $\cdot$ G. Gelbrich

Coordination Center for Clinical Trials, University of Leipzig,

Leipzig, Germany

A. Kockskämper $\cdot$ B. Pieske

Department of Cardiology, Medical University Graz,

Graz, Austria

H. D. Düngen

Department of Cardiology, Charité-Universitätsmedizin Berlin,

Berlin, Germany

M. Scherer

Institute of Social Medicine, University of Luebeck,

Luebeck, Germany

L. Binder

Department of Clinical Chemistry, University of Goettingen,

Goettingen, Germany

C. Herrmann-Lingen

Department of Psychosomatic Medicine,

University of Goettingen,

Goettingen, Germany 